Etnográfica

Revista do Centro em Rede de Investigação em

Antropologia

vol. 24 (3) | 2020

Vol. 24 (3)

\title{
Casas feitas de olhares: uma etnografia dos muros em um loteamento periférico do Rio de Janeiro
}

Houses made of views: an ethnography of walls in a peripheral plot of Rio de Janeiro

\section{Thomas Jacques Cortado}

\section{(2) OpenEdition}

Journals

Edição electrónica

URL: https://journals.openedition.org/etnografica/9357

DOI: $10.4000 /$ etnografica. 9357

ISSN: 2182-2891

Editora

Centro em Rede de Investigação em Antropologia

Edição impressa

Data de publição: 1 outubro 2020

Paginação: 665-682

ISSN: 0873-6561

Refêrencia eletrónica

Thomas Jacques Cortado, «Casas feitas de olhares: uma etnografia dos muros em um loteamento periférico do Rio de Janeiro», Etnográfica [Online], vol. 24 (3) | 2020, posto online no dia 31 outubro 2020, consultado o 20 janeiro 2022. URL: http://journals.openedition.org/etnografica/9357 ; DOI: https://doi.org/10.4000/etnografica.9357

\section{(c) (;) (9)}

Etnográfica is licensed under a Creative Commons Attribution-NonCommercial 4.0 International License. 


\section{Casas feitas de olhares: uma etnografia dos muros em um loteamento periférico do Rio de Janeiro}

\section{Thomas Jacques Cortado}

A etnografia de um loteamento periférico no Rio de Janeiro sugere que a construção de muros, em vez de significar um encolhimento da sociabilidade pública, afirma a presença constitutiva do outro na organização da vida privada. Em primeiro lugar, os muros (e as cercas) indicam que alguém está tomando conta do lugar, isto é, tornam público o compromisso prático da pessoa com o lugar. Em seguida, os muros (e os portões) dão liberdade e privacidade a cada família, revelando as tendências individualistas e coletivistas que atravessam as "configurações de casas". Enfim, os muros (e as janelas) atuam dentro de uma "economia do olhar": como bem mostra a crença no olho grande, os moradores procuram, através deles, controlar sua exposição ao olhar alheio, enquanto ficam de olho na rua. O artigo conclui defendendo uma abordagem propriamente etnográfica da distinção público-privado, voltada antes para o funcionamento dessa economia.

PALAVRAS-CHAVE: loteamento periférico, arquitetura doméstica, público-privado, relações de propriedade, configuração de casas, olho grande.

Houses made of views: an ethnography of walls in a peripheral plot of Rio de Janeiro - The ethnography of an irregular subdivision in the urban periphery of Rio de Janeiro suggests that walls, rather than the shrinkage of public sociability, affirm the constitutive presence of the others inside private life. First, walls (and fences) indicate that someone is taking care of the place, that is, they make public one's practical commitment with the place. Then walls (and gates) give freedom and privacy to each family, revealing the individualistic and collectivist tendencies that build the "house configurations." Finally, walls (and windows) act within an "economy of eyes": according to the belief in the evil eye, people try to control their exposure to other people's eye, while keeping an eye on them. The article concludes by advocating an ethnographic approach to public-private distinction, which focuses on this economy.

KEYWORDS: urban periphery, domestic architecture, public-private, property relations, configuration of houses, evil eye.

CORTADO, Thomas Jacques (cortado.thomas@gmail.com) - Universidade Estadual de Campinas (UNICAMP), Brasil. 


\section{REVISITANDO A “CIDADE DE MUROS”}

"Even as the walls have come down in Eastern Europe, they are being erected all over Los Angeles”, lamentava Davis (2006 [1990]: 228). O historiador e ativista político denunciava então a militarização da vida urbana na segunda maior cidade dos Estados Unidos, um processo iniciado nos anos 70 e que se caracterizava, entre outros traços, pelo isolamento das classes média e alta dentro de verdadeiras "fortress cities, complete with encompassing walls, restricted entry points with guard posts, overlapping private and public police services, and even privatized roadways" (Davis 2006 [1990]: 244). A imagem da "Fortress City", da cidade corroída pelo crescimento da segregação e pela destruição dos espaços públicos, se tornou desde então um lugar comum da antropologia urbana (Low 1996). Alguns anos depois de Davis lamentar a transformação de Los Angeles, Caldeira confirmou que, em São Paulo, também prevalecia "the security-driven logic of urban enclavization", expressa na proliferação dos condomínios fechados, espaços "fisicamente demarcados e isolados", "socialmente homogêneos" (Caldeira 2003: 259), onde as classes média e alta ficam sob a proteção de guardas armados e sistemas de segurança. Entretanto, o desejo de cercar e fechar não afetava somente quem escolhera morar em "enclaves fortificados": "todos os tipos de moradia na São Paulo atual passaram por processo de enclausuramento" (Caldeira 2003: 291). À semelhança do caso californiano, cercas, barras e muros em São Paulo foram investidos de um valor estético, constituindo "um tipo de linguagem através do qual pessoas de todas as classes expressam não só o medo e a necessidade de proteção, mas também mobilidade social, distinção e gosto", linguagem que a antropóloga batizou de "estética da segurança” (Caldeira 2003: 293-294).

De tão difusa que hoje é a "estética da segurança” nas grandes cidades brasileiras, ela se encontra também nos chamados "assentamentos precários". Assim, no Rio de Janeiro, os riscos de tiroteio e a ocupação dos espaços públicos pelo tráfico de drogas levaram os moradores das favelas a transformar suas casas em "fortalezas", cercando o pedaço delas com muros altos, colocando grades nas janelas e varandas (Cavalcanti 2007: 322). O mesmo anseio de cercar e fechar anima os moradores da chamada "cidade informal": "favela residents' reactions to the so-called 'public security' crisis is not so different from residents of 'formal' neighborhoods, in Rio or elsewhere" (Cavalcanti 2007: 325). Dificulta a percepção do fenômeno, a plasticidade do espaço autoconstruído, o fato de que na favela, "the process of turning houses into 'fortresses' goes hand in hand with the expansion and improvement of houses themselves, including the interior": se muros e cercas protegem as famílias da violência cotidiana, eles também expressam o progresso material delas. Assim, na favela também os desejos de segurança e ascensão social se entrecruzam. Ao lado da "cidade de muros", concluía Cavalcanti, existia uma verdadeira "favela of walls". 
A metáfora da "cidade de muros" tornou-se, portanto, um lugar-comum da antropologia urbana nos últimos anos (Low 1996), por captar a tendência global ao "enclausuramento" dos espaços nas grandes metrópoles. Tal imagem pressupõe, contudo, uma concepção normativa da distinção público-privado, evidente no olhar crítico que os antropólogos costumam trazer a respeito do "enclausuramento". Para Caldeira, "a ideia de sair para um passeio a pé, de passar naturalmente por estranhos, o ato de passear em meio a uma multidão de pessoas anônimas, que simboliza a experiência moderna da cidade, estão todos comprometidos numa cidade de muros" (Caldeira 2003: 301). Por impedir a circulação das pessoas e isolar os grupos sociais, os muros representariam uma ameaça "aos valores modernos de abertura e tolerância à heterogeneidade" - e, portanto, à própria democracia, "tolerante às diferenças sociais e às negociações em encontros anônimos" (Caldeira 2003: 307). Reconhecemos aqui a concepção "romântica" da distinção privado-público, "which sees the 'public' realm as a sphere of fluid and polymorphous sociability, and seeks to analyze the cultural and dramatic conventions that make it possible" (Weintraub 1997: 6). A um domínio privado inner-directed, definido por relações pessoais entre indivíduos que compartilham a mesma origem (idealmente da mesma família), opor-se-ia um domínio público other-directed, para retomar uma distinção de Sennett (2002 [1977]: 5), regido por relações impessoais entre indivíduos estranhos. Assim, a "cidade dos muros" simbolizaria, de modo geral, o triunfo das relações inner-directed sobre as relações other-directed. Até que ponto, porém, essa concepção "romântica" da distinção público-privado, que lembra a clássica oposição entre gesellschaft e gemeinschaft, consegue descrever adequadamente as relações que constituem os espaços subsumidos sob essas duas categorias?

\section{O CASO ETNOGRÁFICO:}

\section{A PROLIFERAÇÃO DOS MUROS EM UM BAIRRO "TRANQUILO"}

Com base no uso que os moradores de um loteamento pobre, situado na periferia do Rio de Janeiro, fazem dos muros, proponho problematizar etnograficamente a distinção entre público e privado - darei a esse loteamento de mais de 15.000 habitantes o nome fictício de Jardim Mato Bonito. ${ }^{1}$ De fato,

1 Entre 2014 e 2016, efetuei 18 meses de trabalho de campo no loteamento do Jardim Mato Bonito, no âmbito da minha tese de doutorado. Durante esse período, realizei perto de 40 entrevistas semiestruturadas com moradores do loteamento, sempre gravadas. Ao material coletado nas entrevistas vieram se juntar outros dados obtidos graças à convivência diária com os moradores (observações e conversas informais, anotadas no diário de campo), aos quais sempre dei nomes fictícios também. Uma primeira versão do texto foi apresentada em 2016, no congresso da Associação Europeia de Antropólogos Sociais (EASA), e outra em 2018, no Museu Nacional (Rio de Janeiro). Quero agradecer particularmente a Benoît de l'Estoile, Consuelo Araos e Federico Neiburg pelos comentários provocativos [continua] 
quem passa pelas ruas asfaltadas desse loteamento se depara com uma sucessão de terrenos cercados por muros de tijolo mais ou menos alinhados, alguns superando os dois metros de altura, inclusive quando o terreno não está ocupado; não raramente, a imponência dos muros no redor do terreno contrasta com a modéstia das construções internas. Comecei por atribuir à "estética da segurança" a razão de tal imponência, achando que os moradores do Jardim também estavam querendo transformar suas casas em "fortalezas". Entretanto, a minha interpretação não condizia com a ênfase quase unânime dos moradores na "tranquilidade" 2 do bairro, que eles mesmo opunham à "violência" de outros lugares, particularmente das favelas.

Para quem vem de fora, não faz muito sentido considerar o Jardim Mato Bonito um lugar tranquilo, já que se trata de um território sob o domínio notório da milícia, uma organização paramilitar clandestina, que obriga os comerciantes a pagar uma taxa de segurança semanalmente, além de cometer outros tipos de delito. Acontece que muitos moradores veem a milícia como uma solução - talvez não correta, mas eficiente - ao problema da criminalidade, pois, além de castigar os ladrões, assaltantes e estupradores, ela impede que o tráfico de drogas tome conta do bairro. Pesquisando em uma favela carioca dominada pela milícia, Mesquita já ressaltou o quanto "as milícias têm sido bem-sucedidas em converter seu domínio pela força em uma espécie de 'serviço público informal', cujo conteúdo seria o exercício da função de polícia” (Mesquita 2008: 243). Como explicar, portanto, o apego dos moradores por cercas e muros?

A minha hipótese é que os muros, ao mesmo tempo em que aparentemente separam os domínios privado e o público, na verdade reafirmam as relações que os atravessam; para reusar um conceito psicanalítico, os muros "denegam" a presença da sociabilidade dita pública na organização da vida dita privada, e reciprocamente. O que está em jogo na construção de muros não é exatamente a segurança material ou psicológica dos moradores, mas sim a complexa construção da privacidade, certo agenciamento das relações inner e other-oriented. Em um texto sobre "the performance of secrecy", Herzfeld já alertava sobre essa sociogênese paradoxal da privacidade: para que a sociedade a reconheça, é preciso que a privacidade seja efetivada (peformed) publicamente (Herzfeld 2009: 135). Isso necessita levar em consideração o julgamento das pessoas com as quais a família convive. Ao mencionar o fato de que, na Grécia rural, as pessoas constroem suas casas de tal modo que os vizinhos não possam ver para dentro delas, Herzfeld ressaltou que "such design features, which defy

[continuação] e generosos. Agradeço igualmente à Fundação de Amparo à Pesquisa do Estado de São Paulo (FAPESP, processo n. ${ }^{\circ}$ 2018/12573-9) por ter possibilitado a concepção definitiva do artigo.

2 Entre aspas as expressões que pertencem ao senso comum dos meus interlocutores no campo. Em itálico constam falas nativas específicas, coletadas através de entrevistas e conversas informais, e palavras em outras línguas que não o português. Entre aspas mas sem destaque encontram-se citações e conceitos emprestados à bibliografia. 
modernist planners' notions of order, require a more or less general agreement that they are socially appropriate and normal; otherwise they would backfire and be treated as evidence of anti-social attitudes" (Herzfeld 2009: 153). $\mathrm{O}$ antropólogo concluía então que "privacy is not only an ego-centered legal entitlement but also a highly public good structured both by the physical fabric of the built environment and by the moral dispositions whereby citizens judge that fabric" (Herzfeld 2009: 157). A etnografia dos muros possibilita justamente entrar na estruturação pública da privacidade - além de oferecer proteção, os muros “configuram” (Elias 2008) relações entre pessoas. É o que pretendo demonstrar, ao explorar três dimensões fundamentais da vida privada para os moradores do Jardim Mato Bonito: primeiro, trago à tona o papel retórico dos muros (e das cercas) na construção das "relações de propriedade" (Hann 1998); segundo, aponto para a importância dos muros (e das portas) na organização das relações familiares e domésticas; enfim, analiso as relações entre muros, olhares e desejos na sociabilidade local. À guisa de conclusão, sugiro um deslocamento no modo como a antropologia tratou da distinção entre público e privado, substituindo a essas categorias uma abordagem etnográfica, centrada no modo como as pessoas cotidianamente lidam com o olhar de cada um, aquilo que chamo de "economia do olhar".

\section{A RETÓRICA DA POSSE:}

\section{MUROS E CERCAS NA CONSTRUÇÃO DAS RELAÇÕES DE PROPRIEDADE}

Assim como outros "loteamentos periféricos" no Brasil, o Jardim Mato Bonito teve uma história fundiária conturbada. ${ }^{3}$ Começou pela compra de uma gleba na então zona rural do Rio de Janeiro por uma companhia privada, que a retalhou em lotes residenciais no início dos anos 50, conforme o projeto de loteamento aprovado pela prefeitura do Rio. Cabia a essa companhia prover as infraestruturas, compromisso que nunca cumpriu, deixando amplas áreas do loteamento cobertas pelo brejo. O que não impediu que vendesse os terrenos a prestação, para uma clientela variada, desde migrantes oriundos do interior até gente da classe média ou alta atraída pela oportunidade de investimento imobiliário ou pela possibilidade de construir uma casa de veraneio. Contudo, a falta de infraestrutura e as enchentes que assolam a região afastaram os compradores de maior poder aquisitivo, muitos abandonando os lotes que tinham comprado, que ficaram vazios. A partir dos anos 80, com a companhia se

3 De acordo com os estudos clássicos sobre periferia (Bonduki e Rolnik 1979; Maricato 1979; Santos 1980), chama-se de "loteamentos periféricos" os assentamentos distantes dos centros urbanos, carentes de infraestrutura, onde prevalece a autoconstrução como modalidade de acesso à casa própria, e que resultam de uma operação legal ou clandestina de parcelamento do solo (diferente das favelas, que resultam de ocupações clandestinas). Para maiores esclarecimentos sobre a tecnologia do parcelamento do solo na periferia do Rio, cf. Cortado (2018). 
retirando do loteamento, multiplicaram-se as invasões, as ocupações clandestinas: moradores que ainda não tinham casa própria se apossaram dos lotes abandonados; alguns grileiros aproveitaram a oportunidade para vender terrenos através de documentos forjados, às vezes recorrendo à violência física para expulsar invasores e proprietários legais. Lembro que, graças à modalidade de usucapião (art. ${ }^{\circ}$ 1242. ${ }^{\circ}$ do Código Civil), a ocupação clandestina pode levar à propriedade legal: desde que a ocupação ocorra de forma "mansa, pacífica e ininterrupta", durante dez anos, o invasor pode pedir à justiça o seu reconhecimento como proprietário legal. Para desestimular a entrada de invasores ou grileiros, ou impedir que os vizinhos "comessem" parte do terreno, os proprietários do Jardim Mato Bonito que ainda não edificaram seus terrenos, mas não desistiram deles, costumam colocar cercas e levantar muros ao redor.

Assim, há duas vias legais para acessar à propriedade no Jardim Mato Bonito: a primeira, com base no contrato, quando a posse do terreno decorre de uma transação registrada no cartório; a segunda, com base só na posse, pacífica e ininterrupta. A coexistência dessas duas vias gera situações confusas, visto que o mesmo lote pode ter sido adquirido contratualmente por um, mas estar ocupado por outro. Os invasores têm ciência da possibilidade de ascender à propriedade por meio da posse, chegando a chamar a si mesmos de posseiros, uma terminologia comum nas áreas rurais do Brasil. De fato, muitos invasores se consideram os verdadeiros donos da terra, já que eles tomam conta dela. A expressão "tomar conta", corriqueira no português das classes populares cariocas, tem vários significados diferentes, indo de cuidar ("a avó toma conta da criança"), mandar ("a milícia é quem toma conta daqui"), e vigiar ("os vizinhos tomam conta da rua"), até ocupar ("os turistas estão tomando conta da praia"), assumir ("o filho tomou conta da empresa") ou possuir ("o espírito tomou conta dele"). Esses vários significados resumem as ideias que os moradores têm a respeito da propriedade: o proprietário, ou melhor, o dono, é aquele que "cuida de seu terreno, manda nele e o vigia". ${ }^{4}$ Há, contudo, a possibilidade de delegar para outra pessoa, muitas vezes um vizinho conhecido, a responsabilidade de vigiar o terreno e cuidar dele ("ele pediu para o vizinho tomar conta do terreno"). Em todos os casos, a presença do dono é obrigatória, mesmo que seja uma proxy presence (Dalakoglou 2010): os moradores dizem do dono que não está tomando conta de seu terreno que ele sumiu. Cercar e fazer muro sinalizam então que o dono está tomando conta; cercas e muros funcionam como proxy presence do dono, frente aos potenciais invasores ou grileiros. Já um lote desprovido de limitação física, cerca ou muro, vai ser visto pelos moradores como um "terreno sem dono ou cujo dono sumiu".

4 Conforme mostrou l'Estoile, a categoria cultural de dono não é de natureza econômica, e por isso não pode ser tomada como sinônimo de proprietário: é uma categoria moral e política na medida em que "it refers to the possibility to act as a master in one's own house and on one's own piece of land" (l’Estoile 2014: S68). Ver também Woortmann (1987: 28). 
Para os posseiros, cercar e levantar muros fazem parte do "apossamento". Enquanto os grileiros recorrem à violência e à falcatrua, os posseiros sabem que a sua permanência no mesmo terreno depende de como eles estão tomando conta dele, "cuidando" dele. Embora não conhecessem todas as sutilezas do direito brasileiro, muitos guardam cuidadosamente suas contas de luz, de água e os recibos do IPTU, caso tenham que comprovar a ocupação efetiva do terreno. De modo geral, o posseiro busca deixar visível seu compromisso com o terreno, distinguindo-se do "dono que sumiu". Carlinho, um biscateiro que se apossou de um terreno nos meados dos anos 80, explicou para mim o que é preciso fazer para permanecer em um lote invadido, usando uma expressão típica do linguajar popular carioca: "cair pra dentro".

“CARLINHO: Você não pode ficar olhando pro terreno: 'aquele é meu', não é assim. Limpa o terreno, paga o IPTU e cai pra dentro [...].

THOMAS: Quando tu fala 'cair pra dentro' é o que?

CARLINHO: Quando eu falo cair pra dentro é você cercar, limpar o terreno e começar a fazer obra. Cair pra dentro. É só cercar e deixar lá não. É cair, fazer alguma coisa, e tu bota um poste de luz, com seu nome, que é um documento, que já marca ali o tempo que você, a luz tá marcando, o tempo tá marcando ali. Então você falou e você prova que 'ô, tô aqui, nesse tempo tudo'”.

"Cair pra dentro", "cair em" ou "cair pra" significa participar voluntariamente de certa atividade, muitas vezes de natureza festiva ou lúdica, como no caso da expressão "cair no/pro samba". "Cair pra dentro" sugere, portanto, um compromisso prático da pessoa. Já no caso do "apossamento", esse compromisso prático se dá no ato de atribuir ao terreno um valor de uso, de fazer com que ele se torne habitável para o ser humano, através de atividades que exigem "trabalho": cercar, mas sobretudo limpar e fazer obra. Assim, a ética da posse converge com a concepção moral do trabalho e da terra que o Woortmann descreveu no seu estudo da ordem moral camponesa: em ambos os casos, a transformação prática da terra pelo "trabalho" cria um vínculo pessoal e duradouro com ela (Woortmann 1987; cf. também Hetherington 2009).

Vale ressaltar que as operações mencionadas por Carlinho, ao mexerem com o ambiente físico do lote, têm um impacto visual nítido. "Limpar o terreno, fazer obra" tornam imediatamente público, ou seja, deixam visível para qualquer um o compromisso do dono ou posseiro com ele, o fato de que está "tomando conta" do terreno, ao não deixar "o mato tomar conta dele". Em outras palavras, os atos de cercar e levantar muros devem ser entendidos dentro do que a jurista Rose chamou de rethoric of property. "Possession as the basis of property ownership, then, seems to amount to something like yelling loudly enough to all who may be interested. The first to say, 'This is mine,' in a way that the public understands, gets the prize, and the law will help him keep it against someone 
else who says, 'No, it is mine.'” (Rose 1994: 16). O objetivo da propriedade, e mais ainda da posse, não se reduz à privatização de determinadas coisas, mas envolve também o ato de convencer determinada audiência (a justiça ou potenciais invasores e grileiros) de que "o dono está tomando conta" de seu bem.

\section{GEOPOLÍTICA DA PRIVACIDADE: MUROS, PORTAS E PORTÕES NA ORGANIZAÇÃO DA VIDA DOMÉSTICA E FAMILIAR}

A gente pensa a casa como abrigo e dar aos muros a função de proteger os habitantes da natureza ambiente (e dos inimigos). Entretanto, a casa não só satisfaz essas necessidades básicas, ela atua como categoria sociocultural, ${ }^{5}$ categoria cuja centralidade para as classes populares brasileiras a antropologia já documentou muito bem (Heredia 1979; Heye 1980; Woortmann 1982; Garcia 1983; McCallum e Bustamante 2012; Motta 2013). A importância da casa tem a ver com o que Woortmann chamou de "ideologia da família nuclear": "contrariamente a outras sociedades, como alguns países da África Ocidental e o México, no caso brasileiro, a família extensa e seus correspondentes arranjos residenciais é negativamente valorizada" (Woortmann 1982: 120). Tal ideologia tem fundamento na oposição entre "família" e "parente": enquanto a família abrange o casal marido-esposa e seus filhos, os parentes remetem ao conjunto das pessoas ligadas à família por consanguinidade ou afinidade. Como diz o ditado "parente é serpente", essa oposição pode assumir contornos dramáticos, e de fato ela muitas vezes ressoa nas histórias de vida dos moradores. César por exemplo, técnico em refrigeração, já tinha sua casa antes de vir para o Jardim Mato Bonito, mas a vendeu para se afastar da sogra e das irmãs da esposa, com as quais essa brigava muito. "Quem mora perto de parentes é um problema seríssimo", disse ele, "você acaba vivendo os problemas deles e eles vivendo o teu", pressupondo assim que os problemas dos parentes não eram os problemas dele.

A casa, portanto, é o espaço onde as pessoas atualizam o seu ideal da família, a "contrapartida material" da família nuclear, para retomar a expressão de

5 Junto com várias pesquisas que estão sendo realizadas por antropólogos ligados ao projeto "Formas de governo e práticas econômicas ordinárias" ( $<$ http://ecogov.weebly.com/ $>$ ), a nossa contribuição faz parte de um esforço coletivo para construir uma "nova antropologia da casa", diferente das antropologias clássicas que pensavam a casa como "tipo de habitação". Essa "nova antropologia da casa" (Cortado 2020) encontra-se no cruzamento de duas tradições antropológicas. A primeira, empírica, remete aos estudos clássicos sobre casas, hierarquias e classes sociais no Brasil (Freyre 2006 [1933]; Palmeira 1977; Lopes et al. 1979; Heredia 1979; Woortmann 1982; Garcia 1983). A segunda, teórica, refere à crítica das abordagens estrutural-funcionalistas nos estudos de parentesco, crítica baseada nas definições nativas do parentesco (Yanagisako 1979; Schneider 1980 [1968]). Inspiram também essa "nova antropologia da casa" tentativas teóricas inovadoras de usar o conceito de casa para repensar o parentesco (Lévi-Strauss 1984; Carsten e Hugh-Jones 1995; Carsten 2004). A tese de Louis Marcelin, muitas vezes citada mas infelizmente nunca publicada, sobre a invenção da família afro-brasileira foi o primeiro trabalho a reunir essas várias tradições (Marcelin 1996). 
Woortmann: através da casa, o marido-pai e a esposa-mãe cumprem os papéis definidos pela ideologia da família nuclear, o de "pai de família" para o marido-pai e de "dona de casa" para a esposa-mãe. Contrário àqueles papéis seriam vários pais de família e donas de casa morando na mesma casa, e, reciprocamente, o sentido geral da casa não aceita mais de um pai de família ou dona de casa morando na mesma habitação - arranjos temporários são sempre possíveis e muito comuns, quando o filho mora com a esposa na casa do pai até terminar sua casa, por exemplo, mas esses estão sempre vistos como temporários. Conforme outro ditado que os meus interlocutores citaram inúmeras vezes: "quem casa quer casa". O que torna o espaço da casa tão essencial à família é o princípio cultural da "privacidade". O caso de Arnaldo, biscateiro de 50 anos, nascido no Jardim Mato Bonito, revela o valor dado pelos moradores à privacidade, assim como as dificuldades e soluções encontradas para garanti-la. Hoje separado, Arnaldo teve quatro filhos. Alguns anos atrás, o caçula engravidou uma jovem do Jardim Mato Bonito, que por isso foi expulsa da casa dos pais. Sem lugar onde morar, o casal ficou no terreno do Arnaldo. Quando a neta nasceu, Arnaldo resolveu "dividir" a casa com o seu filho: o quarto grande e o banheiro ficaram com o filho enquanto Arnaldo moraria na sala e na cozinha. Daí Arnaldo fechou a porta que tinha entre o quarto e a sala.

"ARNALDO: Não tem como cara, viver um com outro, a privacidade, cê não tem privacidade. Tem que ter privacidade! Cê quer andar dentro da tua casa normal, quer receber visita, aí tá tudo junto. Vou dizer uma coisa: quem casa quer casa, o que sempre falei contigo, quem casa quer casa. Falei com ele: então fica com essa casa aí cara!”

Arnaldo não parou aí: depois de fechar a porta, abriu outra no antigo quarto, agora casa do filho, para que a família desse possa entrar pelo quintal. Ainda insatisfeito, fechou essa entrada, quebrou parte do muro que cerca o terreno e abriu outro portão, para a família do filho ter sua entrada independente.

O caso do Arnaldo mostra uma série de manipulações ao mesmo tempo simbólicas e arquitetônicas, necessárias para que as relações entre o filho, a nora e o futuro neto compusessem uma "família". E formar uma família é o mesmo do que dar ao marido-pai e à esposa-mãe "privacidade". Essas manipulações seguem basicamente o mesmo padrão: fechar portas colocando muro, e abrir outras quebrando muro, até formar casas diferentes, "divididas". De fato, no Jardim Mato Bonito, esse é um jeito muito comum de fazer novas casas. Assim, as pessoas dependem muito de muros para manter sua privacidade; reciprocamente, quando os muros começam a desmoronar, as pessoas perdem sua privacidade e sobem as tensões entre famílias. A esse respeito, a explicação que César deu à difícil convivência com os parentes é muito instrutiva: "minha casa era muro com ela assim. A gente comunicava do muro, tinha até 
um buraco assim que da minha sala eu via na sala dela, no muro". Ou seja, a família precisa de um espaço exclusivo para atuar como família, e essa é uma das principais razões pelas quais as pessoas levantam muro: para demarcar o espaço da família, lócus da privacidade.

Além do mais, a fala do Arnaldo revela uma proximidade entre privacidade e alguns aspectos concretos do "governo" doméstico, no sentido dado por Foucault do "governo de si e dos outros": a casa é o lugar onde o marido-pai e a esposa-mãe têm pleno controle sobre seus movimentos ("cê quer andar dentro de tua casa normal”), mas também sobre os movimentos de quem está dentro ("você recebe visita, não quer todo mundo misturado"). Ou seja, a casa é o lugar onde o marido-pai e a esposa-mãe exercem sua soberania. Daí a associação frequente nos discursos dos meus interlocutores entre "privacidade", "liberdade" e "independência". "Liberdade" para os moradores do Jardim Mato Bonito significa poder se comportar de acordo com suas regras. Por exemplo, liberdade de andar pela casa de cueca ou de sutiã, liberdade de trocar o canal da televisão quando tiver vontade, liberdade de aumentar o som da música sem causar constrangimento - destaco aqui o duplo sentido da palavra "constrangimento", que remete tanto ao impedimento físico quanto ao incômodo moral. É muito comum pessoas "saírem de casa" só por "sofrer constrangimento", o constrangimento de César por exemplo, que se sentia constantemente espiado pelos parentes. Por isso, levantar muros de modo que cada um tenha sua entrada independente garante a "liberdade", podendo a família andar pela casa sem se sentir "constrangida". Além disso, a entrada independente assegura o controle da família sobre as movimentações dentro de casa. Por exemplo, espera-se do pai de família ou da dona de casa que não deixem qualquer um andar livremente pela casa, sob pena de lançar dúvida sobre a "honra" deles. Ademais, quando as pessoas vão na casa dos outros (parente ou amigo), elas sabem muito bem que estão sujeitas à autoridade dos "donos da casa" - a "boa visita" é aquela que pede licença na hora de passar pela porta da casa. Assim, o apego dos moradores pela entrada independente vai junto com a necessidade de delimitar espaços de soberania doméstica.

O caso de Arnaldo aponta para mais um ponto importante: à primeira vista, o "campo de possibilidades" residenciais acessíveis às classes populares no Brasil não combina com seu "quadro de referência" (L'Estoile 2014: S64), que dá ênfase à "privacidade, liberdade e independência". Entre os maridos-pais e as esposas-mães mais jovens em particular, faltam recursos para comprar uma casa já pronta ou até mesmo para comprar um terreno em cima do qual edificar uma casa. Por isso, muita gente não tem condição para viver longe dos parentes, dos vizinhos e dos amigos, com os quais também compartilham ajuda e afetos. A construção da casa, por exemplo, passa pela mobilização dessas redes, chegando ao seu ápice na hora de "bater a laje", pôr o teto de concreto, o dono chamando então vizinhos, amigos e parentes para ajudar, 
em troca de muita comida e bebida. Algumas tarefas cotidianas, como cuidar das crianças enquanto os pais estão trabalhando, costumam caber aos avós. Por isso, as pessoas fazem suas casas perto dos parentes, às vezes no mesmo lote: muitos filhos fazem suas casas acima da casa dos pais ou nos fundos do terreno, dependendo do espaço disponível, deixando o lote com aparência de vila - "o lote que vira vila" segundo a fórmula que um dos meus interlocutores usou para descrever esse processo.

Em outras palavras, casas só existem dentro do que Marcelin chamou de "configuração de casas", espaço "dans lequel se déroule un processus perpétuel de création et de recréation de liens (réseaux) de coopération et d'échange entre des entités autonomes (les maisons)" (Marcelin 1996: 133). Com efeito, as famílias enfrentam uma contradição entre o ideal da vida doméstica, baseada na independência, e a realidade das práticas domésticas, onde a cooperação, a ajuda, é absolutamente necessária - "les configurations de maisons se construisent dans une structure de tension entre la hiérarchie et l'autonomie, entre le collectivisme et l'individualisme" (Marcelin 1996: 133). Levantar muros acaba sendo um meio de equilibrar essa "estrutura de tensões", de corrigir a discrepância entre o campo das possibilidades residenciais e o ideal da privacidade.

\section{A ECONOMIA DO OLHAR: DESEJOS, MUROS E JANELAS}

Tanto nas relações de propriedade quanto nas configurações domésticas e familiares o olhar sobressai enquanto elemento central da sociabilidade. De fato, o olhar dos outros aparece espontaneamente como o inimigo da privacidade, uma importante função dos muros sendo de proteger a família desse olhar alheio. De novo, chama atenção o exemplo de César: lhe incomodava muito que a sogra pudesse olhar para dentro de sua sala, pelo buraco que tinha no muro, algo que, em português, pode se expressar através de um verbo dificilmente traduzível nas outras línguas, "devassar". O trecho seguinte de uma conversa que eu tive com Afrânio, vigilante aposentado, que mora numa área invadida do Jardim Mato Bonito por mais de 19 anos, ilustra essa associação entre privacidade, muros e olhares:

"AFRÂNIO: Você quando você for fazer sua casa, desculpa de falar isso, se é que você não fez ainda, tem a certeza que você tá certo se fizer primeiro o muro.

THOMAS: Por quê?

AFRÂNIO: Porque você já faz um antepara né. Um muro é um antepara. Chega assim o material, não precisa ninguém estar vendo o que tá chegando, e o que tá saindo, e nem o que você tá fazendo. Dali dentro. Você fecha logo seu trabalho. Na hora que você faz o serviço, a casa tá pronta, ninguém nem tá sabendo o que você tá fazendo, quando você vê a casa pronta.

THOMAS: É que as pessoas gostam de olhar... 
AFRÂNIO: Hi meu camarada! Aqui pergunta: 'mas vem cá, o senhor tá fazendo o quê aqui? O quê que é? Eu deveria ver um lugar pra mim morar. Pra quê isso tudo? Pra quê isso tudo?'. Tem esse tipo de coisa. Ultimamente, o pessoal parou. As pessoas pensavam: 'Uê, vai fazer o quê? Armazém?' porque achava que isso era muito grande. [...] Mas eu acredito que tem o seu muro, que é pra você ficar um pouco em privacidade [enfático], né? E aí fica legal”.

Vale notar que, em nenhum momento, Afrânio levanta o assunto da segurança para justificar a construção do muro. Está na verdade mais preocupado com o olhar das pessoas andando pela rua, sejam elas conhecidas ou não. Preocupações com o olhar dos outros - estranhos, parentes ou vizinhos - foram recorrentes nos discursos dos meus interlocutores e servem para justificar suas decisões arquitetônicas. Em particular, os residentes prestam muita atenção aos lugares onde colocam as janelas, de tal modo que não possam "devassar" a casa do vizinho: com isso, pouquíssimos moradores do Jardim Mato Bonito abrem janelas nas paredes laterais da casa, naquelas que dão no terreno dos vizinhos, a menos que os terrenos estejam separados por muros altos o suficiente.

Além disso, o discurso do Afrânio sugere outra ordem de preocupações, não diretamente relacionada à "privacidade": o olhar das pessoas está sempre cheio de desejos. As falas que Afrânio atribui às pessoas olhando para o terreno dele implicam "inveja”, como se elas cobiçassem o prédio largo que Afrânio estava tentando construir, sendo que as pessoas gostariam de viver num lugar tão grande assim ou de aproveitar o espaço para abrir uma loja. A associação entre olhos e desejos, "inveja” em particular, atravessa a vida cotidiana das classes populares no Rio de Janeiro. Diga-se da criança que fica olhando muito tempo para alguma comida que ela é muito olhuda, que ela é um olhão. Ademais, as pessoas atribuem poderes ao olhar invejoso: independente da religião, todas temem a influência do olho grande ou olho gordo na vida delas, por causar doença e má sorte - e reciprocamente, pessoas que sofrem com doença e má sorte costumam culpar o olho grande, o olhar invejoso dos outros. ${ }^{6}$

Foi o caso do pedreiro José, que mora há sete anos no Jardim Mato Bonito. De todas as pessoas que encontrei, ele foi a que mais se preocupava com a influência do olho grande na sua vida. Há um bom motivo para isso: ao contrário de uma maioria de moradores no Jardim Mato Bonito, José não tem casa própria mas aluga uma quitinete em um prédio que possui mais quinze. Cada

6 Existe uma já longa literatura sobre o "mau olhado", devido à presença de crenças similares em inúmeras culturas indo-europeias e semitas (Maloney 1976). Entretanto, trata-se de uma literatura já antiga, que enxerga o "mau olhado" como uma forma peculiar de feitiçaria (Herzfeld 1981). Estudos mais recentes destacaram a função do "mau olhado" para as interpretações nativas da doença (Rebuhn 1994). Escolhi aqui uma abordagem teórica um pouco diferente, de cunho semiótico, inspirada em Herzfeld (1981) e Abu-Lughod (1986): o olho grande, nesta perspectiva, nos diz algo do modo como as pessoas concebem o lugar do corpo na sociedade. 
lado do prédio tem uma entrada que dá acesso a quatro quitinetes no primeiro andar, mais quatro no segundo, dispostas ao longo do corredor. Com efeito, as janelas de cada quitinete dão diretamente nesse corredor pelo qual transitam os moradores do prédio. Basta andar por ele para ouvir, sentir o cheiro ou olhar dentro das quitinetes de cada um, embora algumas possuíssem cortinas. José, oriundo do interior da Bahia, não gosta daquele prédio, cheio de defeitos, e menos ainda dos vizinhos. Quando o conheci, a esposa dele tinha acabado de dar à luz o primeiro filho dele. Entretanto, por conta do seu alcoolismo, José brigava muito com ela, o que tinha sido o motivo dela não estar presente o dia da entrevista. José culpou então o olho grande dos vizinhos pelo alcoolismo e pelos problemas conjugais.

“JOSÉ: Vou falar pra você ser sincero [eleva o tom da voz, pensando], aqui dentro do Jardim Mato Bonito, tem muita gente aqui [pequena pausa], tem olho grande cara na gente. Tem muito olho grande assim sabe, você não pode construir uma família, você não pode tar com uma mulherzinha bonita que já fica de olho grande, já fica, já dá desavença na família da gente, já começa aquele negócio, o pessoal [...] não precisa nem falar, só fica já curiando as coisas assim cara, tudo curioso".

Depois na conversa, deu exemplo de vizinhos curiando a casa dele.

"JOsé: Eu faço comida boa aqui, e o pessoal, quando faço aqui ó, passa assim ó [imitando a atitude de alguém que estaria olhando pela janela, cheirando a comida; ao mesmo tempo, ouve-se o grito da vizinha]. Entendeu, com essa vizinha não gosto dessa aqui [baixando muito o tom da voz, inaudível]. [...] Aí quando tu passa a conhecer o vizinho é uma merda cara, faz comida, fica de olho. Você não pode fazer nada. O pastor falou bem assim: 'você não pode fazer nada dentro de vila, fica todo mundo de olho', sabe. Todo mundo fica, todo mundo fica de olho. Igual essa daí [baixando o tom da voz] [...] Aqui domingo mesmo eu tava fazendo o meu trabalho aqui e toda hora ela passava. Comida cheirosa que é comida bem temperada aqui, fica tudo de olho, com olho grande e assim com nariz de... viu que são olho grande, a inveja que não sabem fazer aí".

Chamo a atenção como várias expressões remetendo ao olhar, sem pressuposição de alguma presença sobrenatural, na fala do José possuem um duplo sentido, referindo constantemente à ameaça do olho grande. "Ficar de olho", por exemplo, indica tanto o ato de vigiar quanto de colocar o olho grande em alguém. Aliás, faz sentido já que as expressões de olho grande e olho gordo sugerem um mal intrínseco ao olhar, causado por uma extensão do órgão e não por algo exterior ao órgão: basta o "olho crescer" para se tornar maléfico. 
De modo geral, as pessoas encontram dificuldade para avaliar o quanto o olhar dos outros está carregado de inveja, muitas se assustando logo que enxergam alguém olhando para elas. Com efeito, é sempre melhor se proteger do olhar alheio. Qualquer pessoa que possa despertar o desejo dos outros, um homem bem-sucedido, uma mulher bonita ou um lindo bebê, sempre corre o risco de alguém "botar o olho grande" nela. Por isso, mesmo quando a pessoa é conhecida da família, mães e avós costumam não gostar quando ela está olhando para o filho recém-nascido, mesmo que ao olhar se juntem os elogios - especialmente em caso de elogios, pois esses são interpretados como sinais de inveja. Se o bebê ficar doente, é bem provável que mães e avós culpem quem esteve recentemente olhando para o filho. Altos muros, janelas escondidas e entradas separadas reduzem então a "exposição" da família ao olhar invejoso dos outros - mas a condição de inquilino impede José de manipular a arquitetura do seu espaço doméstico para se proteger do olhar alheio.

Contudo, não todos os moradores do Jardim Mato Bonito cercam seus terrenos com muros altos e hermeticamente fechados, pois é preciso "ficar de olho" no que acontece fora da casa, na rua também. Afrânio, que ainda não fez o muro dele, deixou isso muito claro:

"AFRÂNIO: E tenho fobia de coisa fechada na minha frente. Eu quero ver quem tá do outro lado, entendeu. Agora quando fechar, melhor fechar, melhor! Mas não gosto muito de muro fechado. Eu quero ver quem tá passando na minha frente. Eu sempre teve isso. Aí, eu acho que [inaudível] fazer teu muro, uma meia-parede e gradear".

A meia-parede com grade de ferro não é a solução mais comum, mas há outras, como o popular tijolo furado: usado no muro da frente para garantir a ventilação, ele serve também para enxergar a rua sem ser visto. Usar o andar de cima, a laje, como terraço ou varanda oferece um resultado semelhante, pois o dono consegue monitorar a rua sem que alguém possa tirar a privacidade deles. César, por exemplo, cujo muro da frente foi parcialmente feito com tijolo furado, planejou a construção de uma sacadazinha no segundo andar, para "tomar conta da rua". Ou seja, se a gente precisa se proteger do olhar alheio, importa também olhar para as pessoas que andam pela rua.

Entretanto, não se deve concluir que a "economia do olhar" sempre se caracterize por relacionamentos "agonísticos", conforme o paradigma do olho grande. Há também zelo mútuo na forma como os moradores controlam sua

7 Explorando os valores da honra e da humildade entre os Beduínos, Abu-Lughod identificou uma relação estreita entre exposição, vulnerabilidade e fraqueza, relação que, segundo ela, confirmaria o poder explicativo atribuído ao olho gordo (evil eye) nos casos de doença e má sorte (Abu-Lughod 1986: 113-115). O olho gordo, portanto, expressaria a força que o "idiom of exposure" tem de modo geral na cultura beduína. 
exposição ao olhar alheio e atentam uns aos outros. Ao contemplar o enorme muro de concreto que cerca o terreno de sua vizinha, um dos mais altos muros que já vi no Jardim Mato Bonito, Paulo, um carpinteiro que mora lá a seis anos, falou para mim:

"PAULO: Eu não vejo muita graça nesse paredão aí...

THOMAS: Como tu falou né, o problema é que não vê nada...

PAULO: Até pelo estilo da casa você vê ali quem é quem. Parece um presídio! [...] E eu nunca perguntei o porquê que ela fez isso aí e o que que ela pensou fazer. Porque às vezes, você acha que tá fazendo uma coisa pra proteger demais, acaba correndo risco. Porque, como acabou que nós conversamos, alguém entrar de noite aí, como que vai saber que tem alguém aí dentro? Ninguém vai perceber movimento nenhum, é tudo fechado! Não é não? Não tem visão nenhuma".

Assim, o olhar dos outros, em particular o olhar dos vizinhos, também pode ajudar. Afinal de conta, como disse outro morador, "o vizinho é o parente mais próximo”, ou seja, se você está em perigo, a primeira pessoa que pode ajudar você é o vizinho, já que os parentes nem sempre moram do lado. Por exemplo, um caminhão de lixo uma vez destruiu parte do muro do Arnaldo, enquanto ele estava trabalhando. Logo, o vizinho anotou o nome e o número do motorista e ligou para Arnaldo. Arnaldo comentou então comigo: "eu tava trabalhando mas como, como a gente é comunicativo, todo mundo vigia tudo, vigia todo, ajuda como você ajuda os outros eu te ajudo". Ter vizinhos tomando conta, vigiando, olhando para o lugar onde a gente mora oferece, por assim dizer, um seguro contra certos acontecimentos infelizes, assaltos ou acidentes domésticos por exemplo. Consequentemente, muitos moradores constroem muros que escondam o suficiente para "não perder a privacidade", mas que também deixem filtrar um mínimo de informações.

\section{CASAS FEITAS DE OLHARES}

Ao pôr cercas e levantar muros, os moradores do Jardim Mato Bonito procuram, por um lado, proteger suas famílias, defendendo-se de potenciais "invasores", demarcando fronteiras entre as famílias e afastando os perigos do olho alheio, reafirmando a separação entre o domínio dito público e o domínio dito privado. Por outro lado, eles também reconhecem a presença constitutiva desse olhar na construção da vida familiar. O dono legítimo é aquele que "toma conta", que expressa publicamente, ou melhor, torna visível seu compromisso prático com o terreno - o dono que se "sumir" não pode lamentar a perda de sua propriedade. Ao multiplicar as entradas independentes, as pessoas organizam espaços que permitem manter simultaneamente a privacidade e os laços 
afetivos ou de cooperação. Os muros nesse caso produzem um equilíbrio, mas um equilíbrio "flutuante e elástico", um "equilíbrio de poder", uma "configuração" como diria Elias (2008: 143), no meio das tensões entre hierarquia e autonomia, entre "individuação e relacionamento" (McCallum e Bustamante 2012: 224). Enfim, ao edificar muros as pessoas admitem o quanto o olhar alheio é capaz de afetar a vida delas, o quanto, na verdade, elas se sentem expostas, vulneráveis ao olhar dos outros.

Chamo atenção na centralidade do olhar em cada momento da análise. As cercas e os muros que o "invasor" ou o "dono" levanta são feitas para serem vistas, eles enviam um sinal visual às pessoas que passam pela rua, mostrando não só que o terreno "tem dono", mas que "o dono está tomando conta" do terreno: a "retórica da propriedade" também é uma retórica visual. A "liberdade" à qual se referem as pessoas quando falam de "privacidade" também é liberdade de se subtrair ao olhar alheio - andar pela casa de cueca ou de sutiã, convidar quem quiser sem ninguém para espiar, vigiar, monitorar e, portanto, controlar ou comentar a movimentação. As pessoas muitas vezes se sentem "constrangidas" por conta de um olhar percebido como inquisidor. Dentro de universos onde as pessoas "não só se deslocam bastante entre casas [...] como estão muito atentas aos deslocamentos umas das outras", "transform[ando] tal movimentação em foco de narrativa, de julgamento moral, de assunto" (Comerford 2014: 109), contar com uma boa "antepara" é uma vantagem apreciável. A etnografia dos muros se prolonga assim em uma etnografia daquilo que chamei de "economia do olhar", isto é, o modo como os olhares circulam entre as pessoas, dos desejos que animam esses olhares e dos efeitos que eles têm, as tentativas para impedir ou controlar o fluxo dos olhares, conforme o ideal do "ver sem ser visto".

A etnografia dos muros revela, portanto, um fluxo de sociabilidade que desmente a concepção dicotômica da distinção entre público e privado, perpassando a fronteira entre eles: o olhar alheio, o olhar dos outros e não algum olhar impessoal e abstrato, está sempre presente dentro do espaço da casa, mesmo que seja na forma de uma ameaça; do mesmo jeito, há (quase) sempre olhares voltados para a rua, olhares que lhe tiram seu caráter potencialmente "perigoso". Em comparação com as interpretações clássicas, sempre dicotômicas, da distinção entre público e privado no Brasil (Duarte 2006, Holanda 1997 [1936]), a "economia do olhar" me parece um conceito mais adequado para descrever etnograficamente o ordenamento da sociabilidade local. A relação entre a casa e a rua no Brasil não se resume à oposição contrastiva de dois códigos ideológicos (DaMatta 1997), ela é rica de entrelaçamentos práticos e simbólicos, sejam eles conflitivos ou pautados na ajuda mútua. Essa abordagem não necessariamente contradiz o diagnóstico da cidade-fortaleza (Davis 2006 [1990]; Low 2003; Caldeira 2003; Cavalcanti 2007), mas ela leva a tomar muito cuidado na hora de associar a presença de muros ao empobrecimento 
da vida coletiva: muros e cercas podem indicar uma sociabilidade muito mais densa do que parece, um mundo other-directed.

\section{BIBLIOGRAFIA}

ABU-LUGHOD, Lila, 1986, Veiled Sentiments. Berkeley, University of California Press.

BONDUKI, Nabil, e Raquel ROLNIK, 1979, Periferias: Ocupação e Reprodução da Força de Trabalho. São Paulo, USP/FAU.

CALDEIRA, Teresa, 2003, Cidade de Muros. São Paulo, Editora 34/Edusp.

CARSTEN, Janet, 2004, After Kinship. Cambridge, Cambridge University Press.

CARSTEN, Janet, e Stephen HUGH-JONES, 1995, "Introduction”, em Janet Carsten e Stephen Hugh-Jones (orgs.), About the House: Lévi-Strauss and Beyond. Cambridge, Cambridge University Press, 1-46.

CAVAlCANTI, Mariana, 2007, Of Shacks, Houses and Fortresses. Chicago, University of Chicago, Department of Anthropology, tese de doutorado.

COMERFORD, John, 2014, "Vigiar e narrar: sobre formas de observação, narração e julgamento de movimentações”, Revista de Antropologia, 54 (2): 107-142.

CORTADO, Thomas Jacques, 2018 , "Artefacts urbanistiques en périphérie de Rio de Janeiro: la technologie du lotissement", Vibrant, 15 (1): 1-28.

CORTADO, Thomas Jacques, 2020, "Maison", Anthropen.org. Paris, Edition des Archives Contemporaines. DOI: https://doi.org/10.17184/eac.anthropen.131.

DALAKOGLOU, Dimitris, 2010, "Migrating-remitting-'building'-dwelling: house-making as 'proxy' presence in postsocialist Albania", Jornal of the Royal Anthropological Institute, 16: 761-777.

DAMATTA, Roberto, 1997, A Casa e a Rua: Espaço, Cidadania, Mulher e Morte no Brasil. Rio de Janeiro, Rocco Digital.

DAVIS, Mike, 2006 [1990], City of Quartz. Londres e Nova Iorque, Verso.

DUARTE, Nestor, 2006, A Ordem Privada e a Organização Nacional. Brasília, eBooksBrasil.

ELIAS, Norbert, 2008, Introdução à Sociologia. Lisboa, Edições 70.

FREYRE, Gilberto, 2006 [1933], Casa-Grande e Senzala. São Paulo, Global Editora.

GARCIA, Afrânio R. Jr., 1983, Terra de Trabalho. Rio de Janeiro, Paz e Terra.

HANN, Chris, 1998, "Introduction: the embeddedness of property", em Chris Hann (org.), Property Relations. Cambridge, Cambridge University Press, 1-33.

HEREDIA, Beatriz, 1979, A Morada da Vida. Rio de Janeiro, Paz e Terra.

HERZFELD, Michael, 1981, "Meaning and morality: a semiotic approach to evil eye accusations in a Greek village”, American Ethnologist, 8 (3): 560-574.

HERZFELD, Michael, 2009, “The performance of secrecy: domesticity and privacy in public spaces”, Semiotica, 175 (4): 135-162.

HETHERINGTON, Kregg, 2009, "Privatizing the private in rural Paraguay: precarious lots and the materiality of rights", American Ethnologist, 36 (2): 224-241.

HEYE, Ana Margaret, 1980, "A questão da moradia numa favela do Rio de Janeiro ou como 
ter Anthropological Blues sem sair de casa", em Gilberto Velho (org.), O Desafio da Cidade. Rio de Janeiro, Campus, 117-142.

HOLANDA, Sergio Buarque de, 1997 [1936], Raizes do Brasil. Rio de Janeiro, Companhia das Letras.

L'ESTOILE, Benoît de, 2014, “'Money is good, but a friend is better': uncertainty, orientation to the future, and 'the economy" ", Current Anthropology, 55 (S9): S62-S73.

LÉVI-STRAUSS, Claude, 1984, Paroles Données. Paris, Plon.

LOPES, José Sérgio Leite, et al. (orgs.), 1979, Mudança Social no Nordeste. Rio de Janeiro, Paz e Terra.

LOW, Setha, 1996, "The anthropology of cities: imagining and theorizing the city", Annual Review of Anthropology, 25: 383-409.

LOW, Setha, 2003, Behind the Gates. Nova Iorque e Londres, Routledge.

MALONEY, Clarence (org.), 1976, The Evil Eye. Nova Iorque, Columbia University Press.

MARCELIN, Louis Herns, 1996, L'Invention de la Famille Afro-Américaine: Famille, Parenté et Domesticité parmi les Noirs du Recôncavo da Bahia. Rio de Janeiro, Universidade Federal do Rio de Janeiro, PPGAS, tese de doutorado.

MARICATO, Ermínia (org.), 1979, A Produção Capitalista da Casa (e da Cidade) no Brasil Industrial. São Paulo, Alfa-Omega.

MCCALlUM, Cecília, e Vânia BUSTAMANTE, 2012, "Parentesco, gênero e individuação no cotidiano da casa em um bairro popular de Salvador da Bahia”, Etnográfica, 16 (2): 221-246.

MESQUITA, Wania Amélia Belchior, 2008, “Tranquilidade' sob uma ordem violenta: o controle social da 'mineira' em uma favela carioca”, em Luiz Antônio Machado da Silva (org.), Vida sob Cerco. Rio de Janeiro, Nova Fronteira, 227-248.

MOTTA, Eugênia, 2013, "Houses and economy in the favela", Vibrant, 11 (1): 118-158.

PALMEIRA, Moacir, 1977, "Casa e trabalho: nota sobre as relações sociais na plantation tradicional”, Contraponto, 2: 103-114.

REBUHN, Linda-Anne, 1994, "Swalling frogs: anger and illness in Northeast Brazil", Medical Anthropology Quarterly, 8 (4): 360-382.

ROSE, Carol M., 1994, Property and Persuasion. Boulder, CO, Westview.

SANTOS, Carlos Nelson Ferreira, 1980, "Velhas novidades nos modos de urbanização brasileiros", em Lícia do Prado Valladares (org.), Habitação em Questão. Rio de Janeiro, Zahar, 17-48.

SCHNEIDER, David M., 1980 [1968], American Kinship. Chicago, The University of Chicago Press.

SENNETT, Richard, 2002 [1977], The Fall of Public Man. Londres, Penguin Books.

WEINTRAUB, Jeff, 1997, "The theory and politics of the public/private distinction”, em Jeff Weintraub e Krishan Kumar (orgs.), Public and Private in Thought and Practice. Chicago e Londres, The University of Chicago Press, 1-42.

WOORTMANN, Klaas, 1982, “Casa e família operária”, Anuário Antropológico, 8: 119-150. WOORTMANN, Klaas, 1987, “'Com parente não se neguceia’: o campesinato como ordem moral”, Anuário Antropológico, 12: 11-73.

YANAGISAKO, Sylvia J., 1979, "Family and household: the analysis of domestic groups", Annual Review of Anthropology, 8: 161-205. 